\title{
Prostaglandines, Trombose en Bloedingen
}

\author{
M. Verstraete \\ Centrum voor Thrombose en Vasculair Onderzoek, Departement Medische Navorsing, Campus Gasthuisberg, \\ Herestraat 49, 3000 Leuven, België
}

\section{UITTREKSEL}

Als groep bestaan de prostaglandines (PG) uit een vijfhoekige koolstofring met zuurstofsubstituenten en twee lange, evenwijdige koolstofketens. Volgens de precieze samenstelling van de pentaanring worden zij met de letter $A$ tot I genoemd (bijv. prostaglandine F), de index wijst op het aantal dubbele bindingen in de zijketen (bijv. prostaglandine $F_{1}$ ) en een Griekse letter duidt aan dat er isomeren bestaan (bijv. prostaglandine $F_{1_{\alpha}}$ ). Alle prostaglandines zijn afkomstig uit essentiële vetzuren met 20 koolstofatomen.

Een essentiëel vetzuur met 3 dubbele bindingen di-homo-y-linolzuur (eicosatriënoinezuur; C 20:3) is de praecursor van de prostaglandines met één dubbele binding (index 1), arachidonzuur (eicosatetraënoinezuur; $C 20: 4$ ) met zijn vier dubbele bindingen leidt tot prostaglandines met twee dubbele bindingen (index 2) en eicosapentaënoinezuur (C 20:5) tot de prostaglandines met 3 dubbele bindingen (index 3).

Arachidonzuur (C 20:4), het essentiëel vetzuur dat in onze weefsels het meest voorkomt, is de praecursor van verschillende prostaglandines van de 2-groep;welke derivaten precies zullen gevormd worden hangt van het weefsel af. In de bloedplaatjes is er het enzyme thromboxaansynthetase dat arachidonzuur tot thromboxaan $A_{2}\left(T X A_{2}\right)$ omzet, een sterke inductor van de bloedplaatjesaggregatie en tevens een krachtige vasoconstrictor. Ter hoogte van het vasculair endotheel zal een ander enzym, prostacyclinesynthetase, arachidonzuur tot prostacycline (PGI, omzetten, dat een krachtige remmer is van de bloedplaatjesaggregatie en een vasodilatator. Thromboxaan $A_{2}$ en prostacycline hebben dus tegengestelde effecten; zij ontstaan evenwel uit dezelfde praecursoren en zijn beiden even labiel (halfleven van minder dan 220 seconden).

Thromboxaan kan beschouwd worden als een calciumionophoor waardoor calcium van het dens tubulair stelsel naar het cytoplasma van de bloedplaatjes overgaat; vrij calcium zal er het contractieel eiwit actomyosine activerenen aldus de contractie van het bloedplaatje induceren. Deze vormverandering van het bloedplaatje van de schijfvorm tot een doornig bolletje is nodig opdat zij zouden kunnen met elkaar in contact komen en aggregeren.

Prostacycline remt deze aggregatie door adenylcyclase in de bloedplaatjes te stimuleren waardoor de concentratie van cyclische adenosine monofosfaat (cyclisch AMP) stijgt en uiteindelijk calciumionen vanuit het cytoplasma in het dens tubulair stelsel teruggevoerd worden; aldus relaxeert het bloedplaatje. Dit is het anti-aggregerend effect van in endotheelcellen gevormde en door de vaatwand afgegeven prostacycline.

1. Het prostaglandinestelsel kan aanleiding geven tot een verhoogde bloedingsneiging.

1.1 Eskimo's hebben een verlengde bloedingstijd en doen ook veel minder atherosclerose. Het is bekend dat Eskimo's veel vis eten welke omzeggens geen arachidonzuur bevat, maar rijk is aan eicosapentaënoinezuur (C

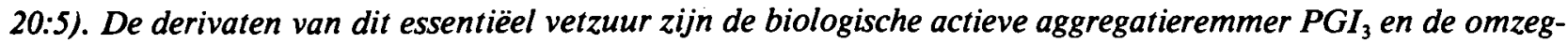
gens biologisch inactieve aggregatieinductor thromboxaan $A_{3} ;$ het evenwicht tussen beide biologishe effecten is dus verstoord ten gunste van de aggregatieremming.

1.2 Na inname van acetylsalicylzuur bij gebruikelyje dosering is eveneens de bloedingstijd verlengd. Aspirine en veel andere niet-steroidale anti-inflammatoire middelen remmen cyclo-oxygenase minder lang in endotheelcellen dan in bloedplaatjes zodat de prostacyclinevorming domineert op de thromboxaanvorming.

1.3 Patiënten met een congenitale familiale deficiëntie van thromboxaan synthetase hebben een bloedingsneiging.

1.4 Patiënten met nierinsufficiëntie hebben een bloedingsneiging die vermoedelijk toe te schrijven is aan de aanwezigheid in het bloed van een plasma-eiwit dat de vorming van prostacycline in de vaatwand stimuleert, zodat het anti-aggregerend effect in het bloed domineert.

2. Het prostaglandinestelsel kan ook de oorzaak van trombosevorming zljn:

2.I Patiënten met een "lupus anticoagulans" (een immunoglobuline gericht tegen bepaalde fosfolipiden) hebben een verlengde "prothrombinetijd" (door de interactie tussen bloedfosfolipiden en de "stollingsfactoren"' $I I, V$ en $X$ te verhinderen). Dit immunoglobuline vermindert ook de vrijzetting van arachidonzuur uit fosfolipiden en dus de prostacyclinevorming, zodat arteriële trombosen in $25 \%$ der gevallen voorkomen. Ook het feit dat deze patiënten recidiverende misvallen hebben kan door verminderde prostacyclinevorming verklaard worden.

2.2 Patiënten met thrombotisch thrombocytopenische purpura en met het hemolytisch-uremisch syndroom doen intravasale stolling; in hun plasma ontbreekt een factor die de prostacyclinevorming stimuleert. Er wordt door het vaatendotheel minder prostacycline gevormd als ratten na streptozotocine-inspuiting diabetes ontwikkelen. Ook diabetici vormen minder prostacycline dan niet-diabetici van hetzelfde geslacht, leeftijd en gewicht. 
ABSTRACT

\section{Prostaglandins and thrombosis formation}

As a group, postaglandins ( $P G)$ are composed of a pentagonal carbonring with oxygensubstitutes and two long parralel carbonchains. According to the precise composition of the pentane ring, they are called by the letters $A$ until $I$ (for instance: prostaglandin F), the subscript numeral points to the number of double bonds in the side chain (for instance: $F_{\nu}$ ) and a Grecian letter shows there exist isomers (for instance: Prostaglandin $F_{\nu}$ ), All prostaglandins proceed from essential fatty acids with 20 carbon atoms. An essential fatty acid with three double bonds, di-homo-ylin-oleic acid (Eicosatrienoic acid, C 20:3) is the precursor of the prostaglandins with one double bond (indicator I); arachidonic acid (Eicosatetraenoic acid, C20:4) with its four double bonds leads to prostaglandins with double bonds (indicator 2) and Eicosapentaenoic acid (C 20:5) to the prostaglandins with three double bonds (indicator 3 ).

Arachidonic acid (C 20:4), the essential fatty acid that we find most in our tissues, is the precursor of different prostaglandins of the 2-group; which derivates will precisely be produced depends upon the tissue. In blood platelets, there is an enzyme called thromboxane synthetase, which converts arachidonic acid into thromboxane $A_{2}$ $\left(\mathrm{TBX} A_{2}\right)$, a strong inductor of the blood platelet aggregation and also a potent vasoconstrictor. In the vascular endothelium, another enzyme, prostacyclin synthetase, will convert arachidonic acid into prostacyclin, which is a powerful inhibitor of platelet aggregation and a vasodilator. Thromboxane and prostacyclin possess contrary effects; and yet they derive from the same precursors and are both equally unstable (halflife of less than 220 seconds).

Thromboxane may be considered as a calcium ionophore, because of which calcium migrates from the dense tubular system to the cytoplasm of the blood platelets; free calcium will activate here the contracting protein actomyosin and induce in this way the contraction of the platelets. This change in the shape of the platelet namely from a disk-like shape to a spiny little sphere, is necessary so that the platelets could come into contact with one another and aggregate.

Prostacyclin reduces the aggregation by stimulating adenylcyclase through which the concentration of cyclic AMP rises and finally calcium ions are taken back from the cytoplasm into the dense tubular system; thus the blood platelet relaxes. This is the antiaggregating effect of prostacyclin, formed in endothelial cells and released by the vascular inner coat.

1. The prostaglandin system may lead to an increased bleeding tendency.

1.1 Eskimo's have a prolonged bleeding time and suffer far less from atherosclerosis. It is a wellknown fact that Eskimo's eat much fish, which contains about no arachidonic acid, but is rich in eicosapentaenoic acid $(C$ 20:5). The derivates of this essential fatty acid are the biologically active aggregation inhibitor $P G I_{3}$, and the almost biologically inactive Thromboxane $A_{3}$, the balance between both biologic effects is tipped in favour of the aggregation inhibition.

1.2 After taking acetylsalicylic acid, in the usual dosage, the bleeding time is also prolonged. Aspirin and many other nonsteroidal anti-inflammatory drugs inhibit cyclo-oxygenase production for a shorter time in endothelial cells than in blood platelets, so that the production of prostacyclin is higher than the production of thromboxane.

1.3 Patients with a congenital familial insufficiency of thromboxane synthetase have a tendency to bleeding.

1.4 Patients with renal insufficiency have a bleeding tendency which may probably be attributed to the presence in their blood of a plasma protein which stimulates the production of prostacyclin in their wall so that the antiaggregating effect is dominating in their blood.

2. The prostaglandin system may also be the cause of thrombosis formation:

2.1 Patients with a lupus anticoagulans (an immunoglobulin directed against phospholipids) have a prolonged prothrombin time lowing to the prevention of the interaction between phospholipids in the blood and the coagulating factors $I I, V$ and $X$ ). This immunoglobulin also reduces the release of arachidonic acid from phospholipids and consequently the prostacyclin production. The fact that such patients also get recurrent miscarriages can be explained by a lower prostacyclin production.

2.2 Patients with thrombotic thrombocytopenic purpura and with hemolytic -uremic syndrome get intravascular coagulation; in their plasma fails a factor which stimulates prostacyclin production. The vessel endothelium produces less prostacyclin in rats which develop diabetes after an injection of streptozotocin. Diabetic patients also produce less prostacyclin than non-diabetics of the same sex, age and weight.

Het is bijna ongeloof waardig dat men in de tweede helft van de twintigste eeuw een groep verbindingen ontdekt, die vrijwel overal in het lichaam voorkomen en waarvan men het bestaan niet vermoedde.

In het begin van deze eeuw werden de eerste waarnemingen gepubliceerd over de invloed van spermavloeistof op glad spierweefsel. Pas enkele jaren later isoleerde Goldblatt ${ }^{1}$ het vetoplosbaar zuur dat in het sperma bij proefdieren baarmoederkontrakties opwekt, een jaar nadien noemde von Euler ${ }^{2}$ deze stof prostaglandine, een naam die achteraf bezien niet juist is omdat deze stof niet van de prostaat maar vrijwel uitsluitend van de zaadblaasjes afkomstig is. Pas in 1960 lukte het de groep van het Karolinska Instituut $^{3}$ twee prostaglandines van elkaar te scheiden door gebruik te maken van twee oplosmiddelen, 
ether en een waterige fosfaatbuffer; zo ontstonden de thans gebruikte termen prostaglandines $E$ en $F$.

De verdere naamgeving van de prostaglandines is ontleend aan het in de natuur niet voorkomende prostaanzuur (Fig. 1a). Het is gekenmerkt door een pentaanring (vijfring) en twee parallellopende zijketens bestaande uit koolstofatomen (in totaal 20 C-atomen). In 1964 ontdekken, onafhankelijk van elkaar, de groep uit Vlaardingen ${ }^{4}$ en de groep van het Karolinska Instituut's de samenhang tussen prostaglandines en het 20 koolstofatoomtellende vetzuur arachidon; arachidonzuur is van het essentiëel vetzuur, linolzuur, afkomstig.

De voornaamste prostaglandines behoren tot de E-, F-, A- en B-groep; het onderscheid is gebaseerd op veranderingen in de pentaanring (Fig. 1b). De stereo-isomere positie van die OH-groep wordt aangeduid door de Griekse letter $\alpha$ of $\beta$.

In feite zijn de thans bekende prostaglandines afkomstig uit drie verschillende essentiële vetzuren die allen 20 C-atomen hebben zoals de term "eicosa" het aanduidt. Eicosatriënoninezuur (di-homo-ylinoleenzuur:C 20:3) leidt tot prostaglandines met één onverzadigde binding in de zijketen, wat aangeduid wordt met het arabisch cijfer 1 (Fig. 2). Eicosatetraënoinezuur (C 20:4) of arachidonzuur leidt tot prostaglandines met 2 onverzadigde bindingen (index 2) en eicosapentaënoinezuur (C 20:5) leidt tot prostaglandines met 3 onverzadigde bindingen (index 3).

Onze essentiële vetzuren zijn niet als dusdanig in de rustende cel aanwezig maar onder meer opgeslagen als fosfolipiden in de celmembranen. Als de cel gestimuleerd wordt, komt adenylcyclase vrij. Deze adenylcyclase vormt intracelllair ATP om tot $\left(3^{\prime}, 5^{\prime}\right)$ cyclisch AMP. Dit intracellulair AMP wordt wel eens een "second messenger" genoemd omdat hij aanleiding geeft tot activering van specifieke celfunkties. Onder meer komen aldus fosfolipasen vrij die de fosfolipiden uit de celmembraan hydrolyseren tot arachidonzuur. Vrijgemaakt arrachidonzuur kan worden gemetaboliseerd door twee verschillende enzymes.

Lipoxygenase II vormt in de bloedplaatjes, longen en leucocyten het vrij instabiele 5- of 12-hydroperoxyeicosatetraënoinezuur (HPETE), dat onder invloed van een peroxydase het stabiele 5- of 12-HETE wordt. Uit dit 5-HETE ontstaan dan de leukotriënen welke sterke chemotactische eigenschappen bezitten.

Een andere mogelijkheid is dat lipoxygenase I op het substraat arachidonzuur inwerkt en eerst 11-HPETE vormt, waarna de alom tegenwoordige cyclooxygenase een cyclische struktuur in de lange koolstofketen invoert door het inbouwen van zuurstof. Aldus ontstaat prostaglandine $\mathrm{PGG}_{2}$, dat via een peroxidase kan omgezet worden tot prostaglandine $\mathbf{H}_{2}$. Die twee laatste intermediaire stoffen worden vaak cyclische endoperoxiden genoemd; zij zijn zeer labiel. Onder invloed van endoperoxideisomerasen ontstaan de drie stabiele endoperoxidederivaten, de prostaglandines $D_{2}, E_{2}$ en $F_{2 \alpha} \cdot{ }^{6}$ In bepaalde omstandigheden kunnen bloedplaatjes voldoende $\mathrm{PGD}^{2}$ vormen zodat een anti-aggregerend effekt ontstaat. ${ }^{7}$ (Fig. 3).

Andere activeringswegen van de labiele endoperoxiden zijn afhankelijk van het weefsel waarin zij zich bevinden. In de bloedplaatjes wordt onder invloed van thromboxaansynthetase vooral thromboxaan $\mathbf{A}^{2}$ gevormd dat spontaan ontaardt in het inactieve thromboxaan $B_{2}$. Thromboxaan $A_{2}$ is een zeer sterke inductor van de bloedplaatjesaggregatie en tevens een krachtige vasoconstrictor. Thromboxaan $\mathrm{A}_{2}$ heeft een halfleven van $30 \mathrm{sec}$. en wordt hoofdzakelijk in de bloedplaatjes gevormd. 8,9 Een ander enzyme, prostacyclinesynthetase vormt uit de cyclishe endoperoxiden prostacycline $\left(\mathrm{PGI}_{2}\right)$ en dit vooral ter hoogte van de endotheelcellen van de vaatwand. Prostacycline remt de bloedplaatjesaggregatie af en dilateert de bloedvaten. $(10,11,12)$. Ook prostacycline is zeer labiel en ontaardt na 120 seconden spontaan tot een inerte stof 6-keto-PGF 1 $_{\alpha}$ of enzymatisch tot 6-15-diketo $\mathrm{PGF}_{\mathrm{t}_{\alpha}}$ (enzyme: 15 hydroxyprostaglandine dehydrogenase). Het is interessant op te merken dat de activiteit van het prostacyclinesynthetase afneemt van het endotheel naar de adventitia van de vaatwand toe terwijl het aggregatiebevorderend collageen vooral in de buitenste lagen van het bloedvat te vinden zijn. Endotheelcellen zijn dus geen inerte niet trombogene voering van het bloedvat, maar hebben een duidelijk actieve rol bij het voorkomen van bloedplaatjesvaatwandinteracties. Endotheelcellen synthetiseren niet alleen prostacycline maar ook stollingsfactoren (o.m. factor VIII) en plasminogeenactivator en tevens collageen, mucopolysacchariden, elastine en fibronectine.

De prostaglandines endoperoxiden bevinden zich dus op het kruispunt van het metabolisme van arachidonzuur. $Z i j$ vormen als het ware een draaischijf van waaruit, afhankelijk van de aard van het weefsel, verschillende metabolieten met tegengestelde effecten kunnen worden gevormd : het aggregerende thromboxaan ( $\mathrm{TXA}_{2}$ ), het antiaggregerend prostacycline $\left(\mathrm{PGI}_{2}\right)$. Men neemt thans aan dat de balans tussen thromboxaan $\mathrm{A}_{2}$ en prostacycline één van de belangrijkste modulerende processen is bij trombotische processen maar-zoals verder wordt onderlijnd-ook voor de normale hemostase. ${ }^{13}$

Om de effecten van prostaglandines op de hemostase te begrijpen is het nodig iets van het mechanisme van bloedplaatjesaggregatie te kennen. Rondstromende bloedplaatjes zijn kernloze schijfjes die deze vorm behouden doordat de membraan opgespannen is door een ring van microtubuli. Twee naast elkaar liggende bollen kunnen elkaar slechts in één punt raken. Ook schijfjes, in feite afgeplatte bollen, zouden te weinig onderlinge contactpunten kunnen hebben om een sterke cohesie te ontwikkelen. Het eerste gebeuren bij bloedplaatjesactivatie is een centripetale beweging van de submembraneuse ring van microtubuli, zodat de bloedplaatjesmembraan niet langer opgespannen staat maar vervormbaar 


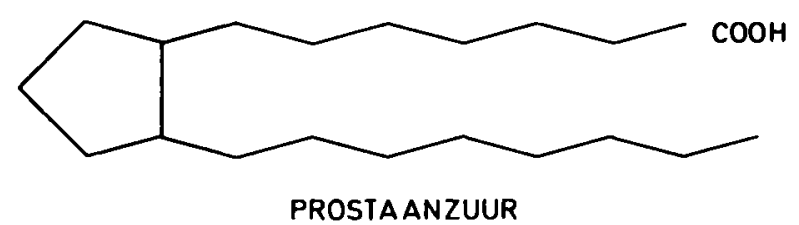

FIGUUR Ia. Structuurformule van het hypothetische prostaanzuur: een pentaanring met twee lange koolstofketens (C 20)

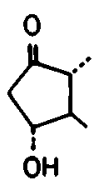

PGE<smiles>CC1C(O)CC(O)C1C</smiles>

PGF<smiles>CC1C(=O)CC(O)C1C</smiles>

PGD

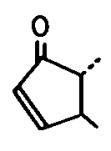

PGA<smiles>CC1=C(C)C(=O)CC1</smiles>

PGB

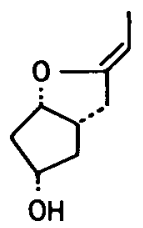

PGI
FIGUUR Ib. Nomenclatuur van de prostaglandines op basis van de samenstelling van de pentaanring

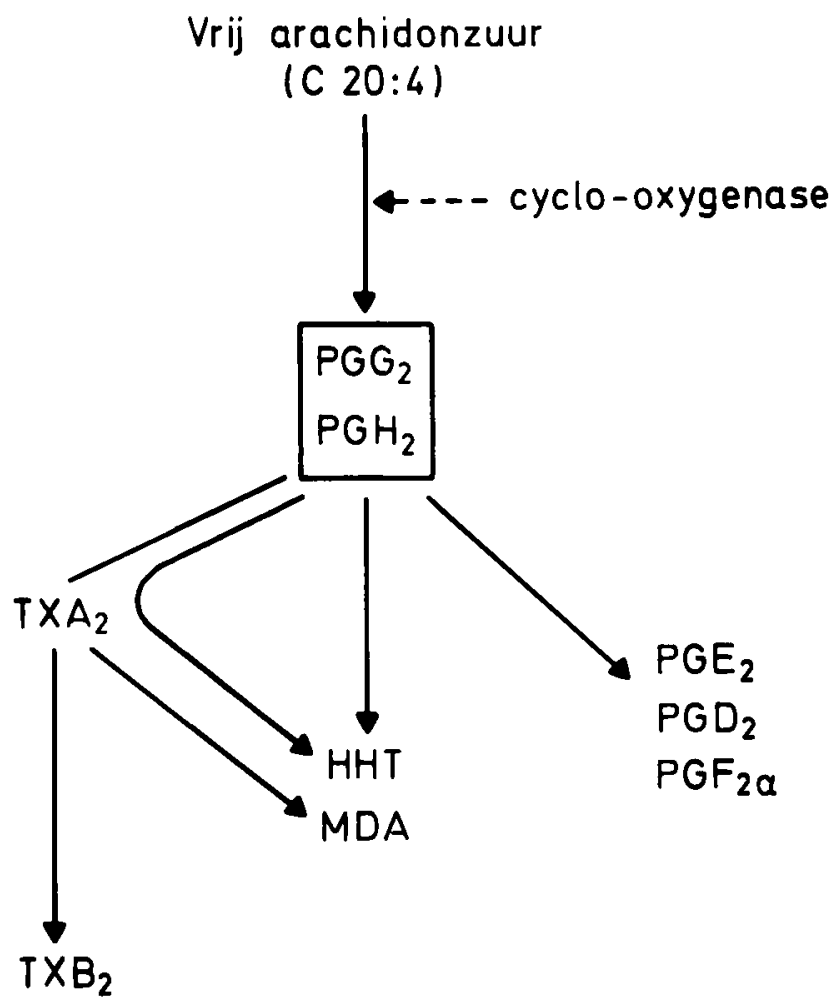

FIGUUR 3. Metabolisme van vrij arachidonzuur in bloedplaatjes

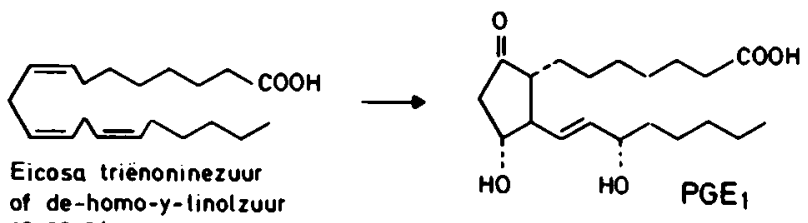

(C 20:3)

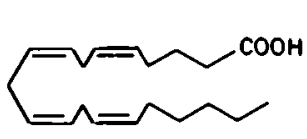

Eicosatetraenoinezuur of arachidonzuur (C 20:4)<smiles>C/C=C\C=C/C=C\C=C/C=C\CCC(=O)O</smiles>

Eicosa - pentaenoinezuur (C 20:5)

FIGUUR 2. Struktuurformules van de voorgangers van de verschillende prostaglandine

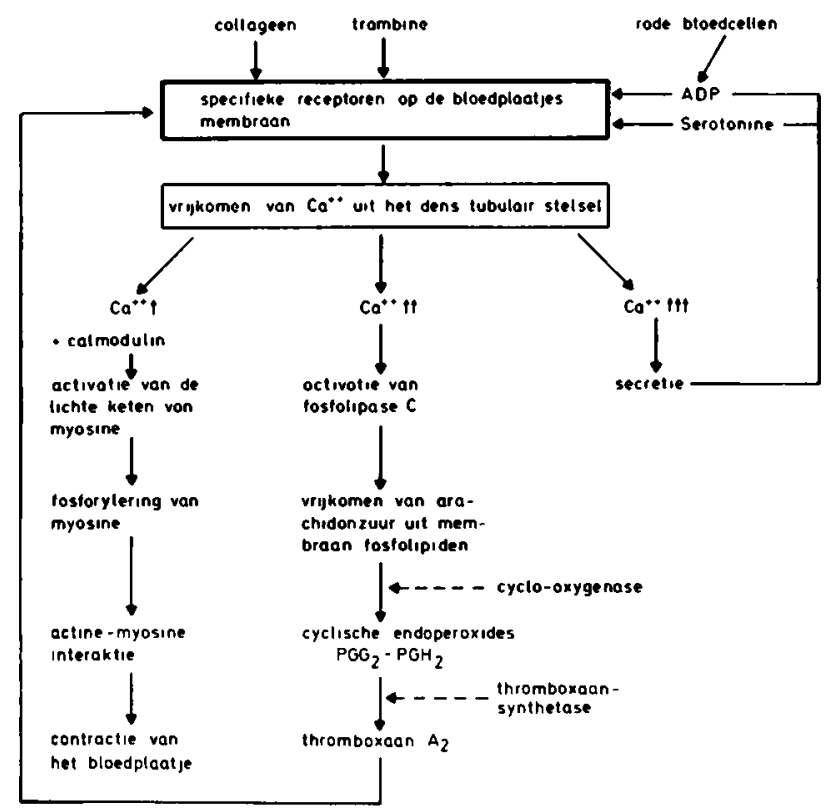

FIGUUR 4. Inductie van bloedplaatjesaggregatie

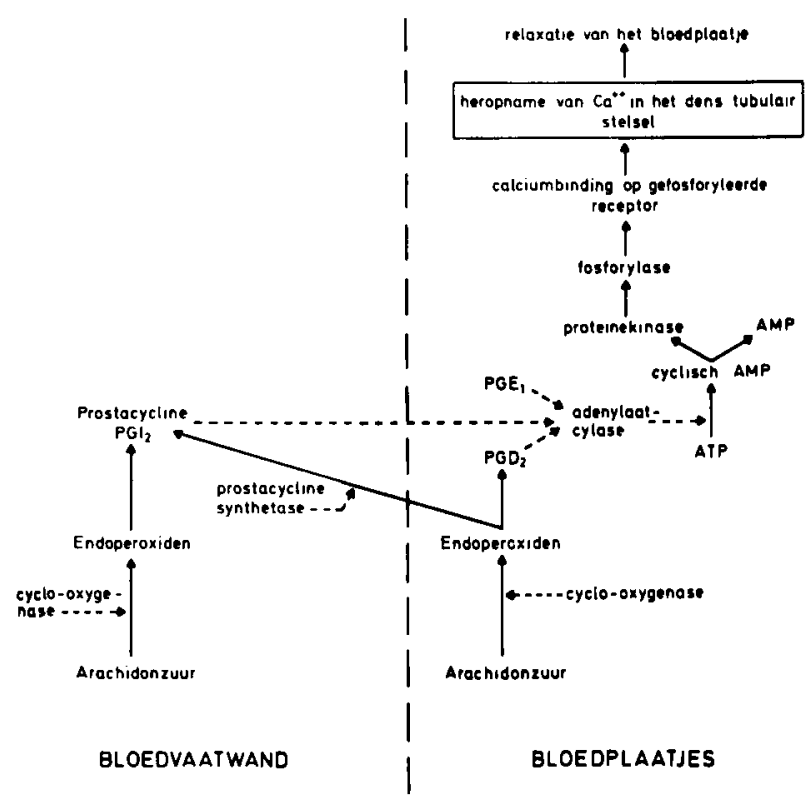

FIGUUR 5. Relaxatie van het bloedplaatje onder invloed van de metabolieten van arachidonzuur 
wordt, waardoor hecht celcontact mogelijk is. Deze centripetale beweging van de submembraneuse ring van microtubuli is de uiting van een intracellulair contractieproces. Inductoren van bloedplaatjesaggregatie, zoals adenosine-5'-difosfaat (ADP), collageen of trombine, zullen na interactie met hun specifieke receptor op het bloedplaatjesmembraan, calciumionen vrijmakem uit het dens tubulair stelsel, dat zich eveneens juist onder de membraan bevindt (Fig. 4). Deze calciumionen die vrijkomen in het cytoplasma zullen, door tussenkomst van calmodulin en een proteinekinase, de lichte keten van myosine fosforyleren, waarna deze zich zal binden aan actinevezels en contractie van het bloedplaatje induceren. Deze calciumionen zullen eveneens fosfolipase $C$ activeren, die fosfatidylinositol in de celmembraan zal opsplitsen in inositol-1-fosfaat en een diglyceride. Van dit laatste wordt door een diglyceridelipase arachidonzuur afgesplitst. Dit arachidonzuur wordt ter hoogte van het dens tubulair stelsel snel omgezet tot thromboxaan $\mathbf{A}_{2}$, dat ten dele de cel verlaat en in andere bloedplaatjes onmiddellijk calcium vrijmaakt en aldus de contractie en vervormbaarheid van bloedplaatjes mogelijk maakt en de mogelijkheid tot nauw celcontact induceert. ${ }^{8}$

Thromboxaan $\mathbf{A}_{2}$ is dus niet verantwoordelijk voor de initiële bloedplaatjesactivatie maar resulteert van deze en is mede verantwoordelijk voor een verdere aangroei van de bloedplaatjesprop. We kunnen dus spreken van een positieve terugkoppeling : bloedplaatjesactivatie-thromboxaansynthese-verdere bloedplaatjesactivatie-nieuwe thromboxaansynthese, enz . . . Het wordt meteen duidelijk dat een beschermend mechanisme moet bestaan om een ongebreidelde groei van de bloedplaatjestrombus te voorkomen.

Het geactiveerd bloedplaatje kan ook relaxeren, de schijfjesvorm herwinnen en zijn affiniteit voor andere bloedplaatjes verliezen. Relaxatie veronderstelt echter heropname van calciumionen uit het cytoplasma en hun fixatie aan membraanstructuren, vermoedelijk opnieuw in het dens tubulair stelsel. (Fig. 5)

De intracellulaire calciumionen worden opgenomen door een eiwit, dat calcium bindt wanneer het gefosforyleerd is. Fosforylering van dit eiwit is afhankelijk van cyclisch adenosine monofosfaat (cyclisch AMP). Cyclisch AMP wordt gevormd uit adenosine trifosfaat onder invloed van het enzyme adenylaatcyclase. Bepaalde prostaglandinen stimuleren dit adenylaatcyclase en verwekken aldus bloedplaatjesrelaxatie; ondermeer prostaglandine $D_{2}$, een krachtige activator van bloedplaatjes adenylaatcyclase. ${ }^{14}$ Normale bloedplaatjes zetten cyclische endoperoxiden voornamelijk om tot thromboxaan $A_{2}$ en slechts in zeer geringe mate tot de stabiele prostaglandinen, waaronder deze prostaglandine $D_{2}$. Prostaglandine $E_{1}$, een metaboliet van eicosatrienoine zuur (C 20:3), activeert ook bloedplaatjes adenylaatcyclase doch heeft vermoedelijk een beperkte rol; evidentie voor de vorming van prostaglandine $E_{1}$ in de omgeving van een hemostatische prop is vrijwel onbestaande.

$\mathrm{De}$ fysiologisch meest belangrijke activator van adenylaatcyclase in bloedplaatjes is prostacycline afkomstig van de vaatwand $\left(\mathrm{PGI}_{2}\right)$. Endotheelcellen kunnen zelf prostacycline vormen uit arachidonzuur; zij kunnen nog meer efficiënt cyclische endoperoxiden, gevormd door bloedplaatjes, "stelen" en omzetten tot prostacycline. Het fysiologisch belang van deze reactie is duidelijk : de bloedplaatjesprop dient om een lek in een gekwetst bloedvat te dichten. Van zodra deze prop zich zal uitbreiden naar het gezond bloedvat toe, zullen de gezonde endotheelcellen de cyclische endoperoxiden, die de geactiveerde bloedplaatjes vormen, onmiddellijk omzetten tot prostacycline. Het prostacycline zal de geactiveerde bloedplaatjes opnieuw hun schijfjesvorm doen aannemen, zodat het bloedplaatjesaggregaat uiteenvalt, de losgekomen bloedplaatjes worden afgevoerd met de bloedstroom en het gezond deel van het bloedvat blijft van trombusvorming gevrijwaard.

\section{Het prostaglandinestelsel en verhoogde bloedings- neiging}

1.1 In onze streken is arachidonzuur het meest voorkomend essentiëel vetzuur in de voeding; alleen bij Eskimo's, met een zeer visrijk diëet, overtreft het gehalte aan eicosapentaënoinezuur (C 20:5) ruimschoots het linulzuur, dat nauwelijks in hun voeding voorradig is. Aldus worden prostaglandinen gesynthetiseerd welke een dubbele binding méér vertonen namelijk drie, dan de prostaglandinen welke wij in onze streken in het menselijk organisme aantreffen. Thromboxaan $A_{3}$ is biologisch niet actief maar het antiaggregerend $\mathrm{PGI}_{3}$ is het wel; dit leidt tot een onevenwicht tussen pro- en anti-aggregerende stoffen ; het anti-aggregerend effect overweegt. Aldus legt men uit dat Eskimo's een verlengde bloedingstijd hebben en minder atheroschlerose doen. ${ }^{15}$

1.2 Patiënten met chronische nierinsufficiëntie hebben een verhoogde bloedingsneiging. Tot voor kort was hiervoor geen afdoende verklaring. Remuzzi en onze vroegere medewerkers, de Gaetano en Donati, ${ }^{16}$ hebben aangetoond dat de vaatwand van uremische patiënten meer prostacycline produceert dan de normale vaatwand en dat uremisch plasma een factor bevat die de vorming van prostacycline door de vaatwand stimuleert, wat wij hebben kunnen bevestigen. ${ }^{17}$ Recent hebben wij deze proeven aangevuld, gebruik makend van een kwantitatieve radioimmuno-assay voor 6-keto-prostaglandine $F_{1}$ (in plaats van een bio-assay) en van endotheelcelculturen (in plaats van rata-ortaringetjes). ${ }^{18,} 19$ Wij vinden dat het molecuulgewicht van de stimulerende factor in uremisch plasma rond de 40.000 is. Verdere karakterisering is aan de gang. Het is duidelijk dat een abnormaal hoge productie van prostacycline door de vaatwand de vorming van een hemostatische bloedplaatjesprop kan belemmeren. 
1.3 Personen die acetylsalicylzuur innemen hebben vaak gastro-intestinale maar ook veralgemeende bloedingen zoals ecchymosen en epistaxis. Aspirine en andere niet-steroïdale antiinflammatoire middelen (NSAID) acetyleren het enzyme cyclo-oxygenase. ${ }^{20}$ Deze remming is irreversibel in de bloedplaatjes omdat deze kernloze protoplasmadeeltjes geen nieuw enzyme kunnen synthetiseren; aldus wordt geen aggregerend thromboxaan $\mathrm{A}_{2}$ meer gevormd. De door acetylsalicylzuur geremde cyclo-oxygenase in endotheelcellen duurt veel korter omdat hierin wel synthese van cyclo-oxygenase plaatsvindt. ${ }^{21,22}$, Daarom heeft slechts een lage dosis acetylsalicylzuur kans een antitrombotisch effect te hebben.

1.4 Er bestaat een congenitale hemorragische diathese veroorzaakt door een cyclo-oxygenase deficiëntie in de bloedplaatjes, die dus geen endoperoxiden uit arachidonzuur vormen. $23,24,25$

1.5 $\mathrm{Bij}$ het onderzoek naar de oorzaak van een congenitale hemorragische diathese hebben wij een familie ontdekt bij wie wij een partiële thromboxaansynthetase deficiëntie van de bloedplaatjes hebben gevonden alsook een daarmee gepaard gaande heroriëntering van het metabolisme van de cyclische endoperoxiden. 26 Het betreft drie familieleden uit drie opeenvolgende generaties met een familiale bloedingsneiging. $\mathrm{Zij}$ hebben afwezige bloedplaatjesaggregatie met arachidonzuur, een sterk verlengde bloedingstijd, alsook verminderde vorming van thromboxaan $B_{2}$ en malondialdehyde. Studie van het metabolisme van radioactief gemerkt arachidonzuur bevestigde de verminderde aanmaak van thromboxaan $\mathrm{B}_{2}$ en van hydroxyheptadecatriënoinezuur (HHT of $\mathrm{C}_{17}$-hydroxyzuur; dit laatste is samen met malondialdehyde een ander endoperoxidemetaboliet via thromboxaansynthetase), maar daarentegen verhoogde productie van prostaglandines $E_{2}, F_{2_{\alpha}}$ en $D_{2}$. Evidentie voor verhoogde productie van prostaglandine $\mathrm{D}_{2}$ werd ook bekomen door de vaststelling dat het cyclisch AMP-gehalte in de bloedplaatjes van patiënten uit dit gezin na stimulatie met arachidonzuur gestegen is. De geactiveerde bloedplaatjes van deze patiënten stimuleerden ook de productie van 6-keto-prostaglandine $\mathbf{F}_{\mathbf{1}_{\alpha}}$ in endotheelcelculturen die vooraf met aspirine waren behandeld. De verminderde productie van thromboxaan $\mathbf{B}_{2}$ en hydroxyheptadecatriënoinezuur en de verhoogde vorming van prostaglandine $E_{2}, F_{2_{\alpha}}$ en $D_{2}$ en prostacycline zijn campatiebel met een partiële thromboxaansynthetase deficiënte van de bloedplaatjes en een heroriëntering van het metabolisme van de cyclische endoperoxiden. De sterk verlengde bloedingstijd zou niet enkel het gevolg zijn van de verminderde vorming van thromboxaan $A_{2}$ maar ook van de verhoogde productie van de aggregatie inhiberende prostaglandines $D_{2}$ en $E_{2}$.
(Fig. 6).

1.6 Deze bevindingen hebben ook duidelijke therapeutische implicaties. ${ }^{27}$ Tot hiertoe werd in een aantal klinische studies het antitrombotisch effect van acetylsalicylzuur bestudeerd, met vrij wisselend resultaat. Acetylsalicylzuur is een inhibitor van cyclo-oxygenase en remt aldus de vorming van thromboxaan $\mathbf{A}_{2}$; het remt daarnaast ook de vorming van de aggregatie remmende prostaglandine prostacycline en prostaglandine $\mathrm{D}_{2}$. Een selectieve thromboxaansynthetaseremmer zou niet alleen de vorming van thromboxaan $\mathbf{A}_{2}$ inhiberen, doch ook, via de heroriëntering van het metabolisme van de cyclische endoperoxiden, de productie van prostaglandine $D_{2}$ en van prostacycline stimuleren. (Fig. 6)

2. De rol van het prostaglandinestelsel in trombogenese

2.1 Inhibitie van prostacyclinevorming door het "lupus" anticoagulans

Wat is het "lupus" anticoagulans? Het is een immunoglobuline, meestal IgG, soms IgM, dat antistofeigenschappen heeft tegenover bepaalde fosfolipiden. Het is geweten dat een aantal stollingsreacties, vooral die waarbij de vitamine K-afhankelijke factoren betrokken zijn, plaats vinden op fosfolipideoppervlakken. Deze stollingsfactoren worden inderdaad op de fosfolipideoppervlakken geadsorbeerd en geconcentreerd; de fosfolipide-oppervlakken hebben dus een catalyserende functie. Wanneer nu dit immunoglobuline met affiniteit voor fosfolipide-oppervlakken deze gaat bedekken, gaat het de catalyserende functie van dit oppervlak storen.28, 29 Het "lupus" anticoagulans komt dus tot uiting in stollingstesten waarin fosfolipiden een rol spelen : de protrombinetijd (of Quicktest) en de partiële tromboplastinetijd zijn licht verlengd. De afwijking wordt veel duidelijker wanneer men de testen herhaalt met verdunde fosfolipide reagentia : hoe geringer het fosfolipide-oppervlak, des te heviger de competitie tussen het immunglobuline en de stollingsfactoren.

Hoe frekwent is het lupus anticoagulans bij lupus? Het zou voorkomen bij 5 a $10 \%$ van de onbehandelde lupuspatiënten, althans wanneer het systematisch wordt opgezocht. Opvallend is nu wel dat er een zeker onderscheid kan gemaakt worden tussen lupus met en lupus zonder anticoagulans. Voor onze uiteenzetting is het paradoxale feit belangrijk dat, waar trombose zeldzaam is bij lupus zonder anticoagulans, ${ }^{30}$ er manifeste arteriële of veneuze trombosen optreden bij een kwart van te lupuspatiënten met anticoagulans.31, 32, 33 Daarenboven hebben patiënten met het lupus anticoagulans geen verhoogde bloedingsneiging.34 De term anticoagulans is dus niet bepaald gelukkig - en dit nog voor een 2 de reden. Het lupus anticoagulans 
komt niet enkel in lupus erythematosus disseminatus voor, maar ook in andere klinische situaties. Het gaat dan vaak om andere autoimmune aandoeningen zoals auto-immune trombocytopenische purpura of chronisch aggressieve hepatitis of nog om myeloproliferatieve aandoeningen. Recent werd de mogelijke associatie van lupus anticoagulans met recurrente abortus gemeld. ${ }^{35}$

We hebben een patiënte bestudeerd die aan een snel voortschrijdende arteriopathie leed met multiepele arteriële occlusies, wiens beide zwangerschappen op 24 weken verwikkeld werden met intra-uteriene vruchtdood en in wiens plasma een lupus anticoagulans werd aangetroffen. ${ }^{36}$ Deze patiënte had geen andere stigmata van lupus erythematosus disseminatus. Het anticoagulans bevond zich in de IgG-fractie. Nu bleek deze IgG-fractie de productie te remmen van prostacycline gevormd door rataortaweefsels, humane endotheelcellen (celculturen) of nog door humaan zwanger myometrium. Daar deze IgG-fractie de productie van prostacycline uit arachidonzuur door deze weefsels niet afremt, is het aangrijpingspunt hoger, namelijk de vrijzetting van arachidonzuur zelf. Zoals vroeger uiteengezet zijn "lupus" anticoagulantia immuunglobulines gericht tegen fosfolipidestructuren. Het lijkt dus aannemelijk dat dit immuunglobuline de vrijzetting van arachidonzuur uit fosfolipide remt.

De uitschakeling van de prostacyclineproductie, een natuurlijk verdedigingsmechanisme tegen bloedplaatjesneerzetting en trombose, kan verantwoordelijk zijn voor de snel voortschrijdende vasculaire pathologie bij deze patiënte. Sinds deze princepsbeschrijving hebben wij nog vijf patiënten bestudeerd met snel voortschrijdende vaatafwijkingen en een lupus anticoagulans, zonder dat zij andere stigmata van lupus hadden. ${ }^{36} \mathrm{Bij}$ alle vijf remde hun plasma de productie van prostacycline af. Wij menen aldus een pathofysiologisch mechanisme ontdekt te hebben dat het ontwikkelen van trombosen bij bepaalde patiënten kan verklaren.

Is er een verband tussen een inhibitor die de productie van prostacycline afremt en recidiverende abortus? Het is geweten dat het gehalte van 6-ketoprostaglandine $F_{1}$ stijgt in het plasma van de moeder tijdens de tweede helft van de zwangerschap. Het zwanger myometrium produceert wel prostacycline, in tegenstelling tot niet-zwanger myometrium. Prostacycline is een krachtige vasodilatator; de locale productie van prostacycline zou bijdragen tot de verhoogde doorbloeding van het myometrium tijdens de zwangerschap. Storing van deze fysiologische reactie zou nadelig kunnen zijn. Daarnaast produceren foetale bloedvaten veel meer prostacycline dan volwassen bloedvaten; dit zou een rol kunnen spelen voor de foetale circulatie, die gekenmerkt wordt door een hoog hartdebiet en een lage perifere weerstand. Transplacentaire overgang van antistoffen die de productie van prostacycline afremmen zou dan ook voor de foetus schadelijk kunnen zijn. Vermylen heeft intussen nog vier patiënten bestudeerd met recurrente intra-uteriene vruchtdood; zij hadden alle vier een lupus anticoagulans zonder andere stigmata van lupus en met afremming van prostacyclineproductie door hun plasma. Wij menen dus een fysiopathologisch mechanisme ontdekt te hebben dat verantwoordelijk kan zijn voor een aantal gevallen van zogenaamde idiopathische recurrente abortus, intrauteriene vruchtdood of intra-uteriene groei-achterstand.

\subsection{De gebrekkige productie van prostacycline bij} het hemolytisch uremisch syndroom en trombotische trombocytopenische purpura

Het hemolytisch uremisch syndroom en trombotische trombocytopenische purpura worden gekenmerkt door een hemolytische anemie van het micro-angiopathisch type, trombopenie en orgaandysfunctie waarin, zeker bij het hemolytisch uremisch syndroom, onder meer de nieren betrokken zijn. Thans wordt volgende samenhang algemeen aanvaard : ingevolge vaatwandbeschadiging (nog nader te preciseren) vormen zich bloedplaatjestrombi in de microcirculatie en wordt hierdoor de orgaanfunctie gestoord; door het uitgebreid tromboseproces worden de bloedplaatjes opgebruikt en de rode bloedlichampjes beschadigd tijdens hun tocht doorheen gedeeltelijk verstopte bloedvaten. Remuzzi en medewerkers ${ }^{37}$ hebben vastgesteld dat de vaatwand van patiënten met hemolytisch uremisch syndroom niet vermag prostacycline te produceren en dat hun plasma, in tegenstelling tot normaal plasma, niet in staat is de productie van prostacycline door "uitgeputte" rataortaringetjes te stimuleren. Dit mogelijk tekort aan een plasmafactor zou de gunstige resultaten verklaren, die gerapporteerd werden bij trombotische trombocytopenische purpura na exsanguinotransfusies of wisselplasmaferese. Remuzzi et al. ${ }^{38,} 39$ hebben derhalve de hypothese geformuleerd dat de trombotische micro-angiopathie een gevolg zou zijn van een prostacyclinetekort.

Wij hebben een patiënte met trombotische trombocytopenische purpura bestudeerd, bij wie het plasmagehalte aan 6-keto-prostaglandine $F_{i_{\alpha}}$ niet meetbaar was vóór wisselplasmaferese maar zich normaliseerde na wisselplasmaferese. ${ }^{40,41}$ Tevens is na deze behandeling de ziekte bij deze patiënte in remissie gegaan. Deze bevinding staaft de hypothese van een tekort aan een plasmafactor, die gecorrigeerd kan worden door plasma-uitwisseling.

Remuzzi et al. ${ }^{39}$ hebben voorgesteld dat een plasmafactor bij sommige patiënten een aangeboren afwijking zou kunnen zijn, waardoor deze patiënten voorbeschikt zijn het 
hemolytisch uremisch syndroom te ontwikkelen. Onze groep heeft een tekort aan de stimulerende plasmafactor kunnen vaststellen bij een reeks kinderen tijdens de acute phase van de aandoening, maar heeft tevens vastgesteld dat na remissie van de ziekte deze plasmafactor wel aanwezig was, hetgeen uiteraard pleit tegen een congenitale deficiëntie van de plasmafactor en in het midden laat of het tekort aan deze plasmafactor een oorzaak dan wel een gevolg is van de aandoening. ${ }^{41}$

De vraag of het tekort aan prostacyclineproductie de oorzaak is van de trombotische micro-angiopathie dan wel het gevolg van de vaataantasting is, is nog onvoldoende beantwoord. Indien tekort aan prostacycline de oorzaak zou zijn van de trombotische microangiopathie, dan zou men verwachten dat het infunderen van prostacycline een onmiddellijk gunstig effect zou hebben op het ziektebeeld. In onze zeer beperkte ervaring bij twee patiënten was dit niet duidelijk het geval.

2.3 Sinds korte tijd is geweten dat de bloedvaten van diabetici minder prostacycline produceren dan normale bloedvaten. Dit houdt mogelijk verband met de verhoogde incidentie van vasculaire complicaties bij diabetici. Wij hebben diabetes bij ratten geïnduceerd door middel van een éénmalige streptozotocine-inspuiting en hebben bevestigd dat de aorta van diabetische ratten minder prostacycline produceert dan de aorta van normale ratten. ${ }^{42}$ Daarnaast hebben wij vastgesteld dat de verminderde productie van prostacycline bij de diabetische ratten ten dele kon gecorrigeerd worden door de dagelijkse toediening van Nafazatrom (Bay g 6575). Klinische evaluatie van Nafazatrom, bijvoorbeeld bij diabetes, lijkt dus wel gewettigd.

Vermelden wij nog in dit verband dat andere auteurs ondertussen ons werk bevestigd hebben, nl. dat nafazatrom de vrijzetting van prostacycline door de vaatwand stimuleert en dat dit gebeurt door remming van een enzyme aanwezig in de vaatwand, 15-hydroxyprostaglandine dehydrogenase.

3. De farmacologische beinvloeding van het prostaglandinestelsel

3.1 Het is bekend dat imidazol de synthese van thromboxaan remt; ${ }^{43}$ wij hebben met een imidazolderivaat (dazoxiben) gewerkt. Deze stof is, zoals imidazol zelf, een remmer van tromboxaansynthetase. Onze in vivo resultaten bij de mens hebben aangetoond dat niet enkel de vorming van thromboxaan $A_{2}$ en hydroxyheptadecatriënoirum (HHT) geînhibeerd wordt (gemeten als thromboxaan $\mathrm{B}_{2}$ en HHT met radioimmuno-assay) doch dit product stimuleert ook de vorming van prostacycline (gemeten als plasma 6-keto-prostaglandine $\mathrm{F}_{1_{\alpha}}$ ) en prostaglandines $\mathrm{E}_{2}$ en $\mathrm{F}_{2_{\alpha}}$ (niet van $\mathrm{PGD}_{2}$ omdat hiertoe serum albumine vereist is); de lipo-oxygenaseproducten worden niet beïnvloed.
Klinische proeven zullen moeten uitmaken of deze selectieve remmer van thromboxaansynthetase een even goed antithromboticum is bij de mens als in experimentele diermodellen.

3.2 Nafazatrom of Bay g 6575 (1-2-( $\beta-$ naphthyloxy)ethyl-3-methyl-2-pyrazoline-5-one) is een stof met krachtige antitrombotische eigenschappen in experimentele diermodellen, dat evenwel geen invloed heeft op de bloedstolling, de fibrinolyse of de gebruikelijke testen van bloedplaatjesaggregatie. Wij hebben evenwel kunnen vaststellen, gebruik makend van een originele techniek (de inductie van bloedplaatjesaggregaten in vivo door veneuse occlusie), dat dit middelbloedplaatjesaggregatie in vivo afremt. Deze bevinding heeft ons op het idee gebracht dat deze stof prostacyclinevrijzetting in vivo zou kunnen stimuleren. Inderdaad hebben wij dan vastgesteld dat plasma genomen na inname van het geneesmiddel veel meer prostacycline vrijmaakt uit rataorta dan plasma van dezelfde persoon vóor inname van het geneesmiddel.44 Waarom wordt dan geen inhibitie van aggregatie waargenomen in de gebruikelijke in vitro testen? Dit komt doordat prostacycline zeer labiel is en dat de stijging van bloedplaatjes cyclisch AMP, welke door prostacycline was verwekt, snel teniet wordt gedaan door het cyclisch AMP afbrekend enzyme, fosfodiësterase. Binnen de tijd die nodig is om bloedplaatjesrijk plasma te bereiden, zou het cyclisch AMP-gehalte reeds genormaliseerd zijn. Wij hebben inderdaad kunnen vaststellen dat na gelijktijdige inname van nafazatrom en een fosfodiësteraseremmer, dipyridamole (deze laatste in een concentratie die zelf geen invloed had op de bloedplaatjesaggregatie), wel duidelijk afremming van bloedplaatjesaggregatie optrad. ${ }^{45}$ Wij hebben eveneens een anti-aggregerend effect van nafazatrom kunnen vaststellen wanneer bloed na inname van dit middel opgevangen werd in een anticoagulans dat ook papaverine bevatte (een andere fosfodiësteraseremmer, en opnieuw bij een concentratie die op zichzelf bloedplaatjesaggregatie niet beïnvloedde).

\section{LITERATUURVERWYSINGS}

1. Goldblatt, M.W. (1933). A depressor substance in seminal fluit, J. Soc. chem. Ind., 52, 1056-1057.

2. Von Euler, U.S. (1934). Zur Kenntnis der pharmakologischen Wirkung von Nativesekreten und Extracten Männlicher Geslechtsdrüssen, Arch. exp. path. Pharmak., $175,78-84$.

3. Bergström, S. \& Sjövall, J. (1960). The isolation of prostaglandin $\mathrm{F}$ from sheep prostate glands, Acta Chem. Scand. $14,1693-1701$.

4. Van Dorp, D.A., Beerthuis, R.K., Neigteren, D.H. \& Vonkeman, H. (1964). Enzymatic conversion of all-cispolyunsaturated fatty acids into prostaglandines, Nature, 203, 839-843.

5. Bergström, S., Danielsson, H., Kleinberg, D. \& Sameulsson, B. (1964). The enzymatic conversion of essential fatty acids into prostaglandins, J. Boil. Chem., 239, 4006-4009.

6. Pace-Asciak, C.R. (1977). Oxidative biotransformation of arachidonic acid, Prostaglandins, 13, 811-817. 
7. Oelz, O., Oelz, R., Knapp, H.R., Sweetman, B.J. \& Oates, J.A (1977). Biosynthesis of prostaglandin $D_{2}$ by human platelets. Prostaglandins, 13, 225-234.

8. Hamberg, M., Svensson, J. \& Samuelsson, B. (1975) Thromboxanes : a new group of biologically active components drived from prostaglandin endoperoxides, Proc. natl. acad. Sci., 72, 2994-2998.

9. Svensson, J., Hamberg, M. \& Samuelsson, B. (1976). On the formation and effects of thromboxane $A_{2}$ in human platelets, Acto physiol, scand., 98, 285-294.

10. Moncada, S., Gryglewski, R.J., Bunting, S. \& Vane, J.R. (1976). An enzyme isolated from arteries transforms prostaglandin endoperoxides to an unstable substance that inhibits platelet aggregation, Nature, 263, 663-665.

11. Moncada, S., Higgs, E.A. \& Vane, J.R. (1977). Human arterial and venous tissues generate prostacyclin (prostaglan$\operatorname{din} X)$, a potent inhibitor of platelet aggregation, Lancet, $i$, 18-21.

12. Moncada, S. \& Vane, J.R. (1977). In Biochemical Aspects of Prostaglandins and Thromboxanes, Kharasch, N. \& Fried, J. eds. (Academic Press, New York) p. 155-177.

13. Moncada, S. \& Vane, J.R. (1978). Unstable metabolites of arachidonic acid and their role in haemostasis and thrombosis, Br. Met. Bull., 34, 129-135.

14. Mills, D.C.B. \& MacFarlane, D.E. (1974). Stimulation of human platelet adenylate cyclase by prostaglandin $D_{2}$, Thrombos. Res., 5, 401-402.

15. Dyerberg, J., Bang, H.O., Stoffersen, E., Moncada, S. \& Vane, J.R. (1978). Eicosapentaenoic acid and prevention of thrombosis and atherosclerosis? Lancet, ii, 117-119.

16. Remuzzi, G., Livio, M., Cavenaghi, A.E., Marchesi, D. Mecca, G., Donati, M.B. \& De Gaetano, G. (1978). Unbalanced prostaglandin synthesis and plasma factors in uraemic bleeding. A hypothesis, Thrombos. Res., 13 , 531-536.

17. Van Hoof, A., Champone, D.A.F. \& Vermylen, J. (1979). Plasma from patients with hepatic or renal failure stimulates prostacyclin release fom "exhausted" rat aorta slices, Thrombos. Haemost., 42,43.

18. Vermylen, J. \& Chamone, D.A.F. (1980). In Hemostasis, Prostaglandins and Renal Disease, Remuzzi, G., Mecca, G. \& de Gaetano, G. eds. (Raven Press, New ork) p. 243-249.

19. Defreyn, G., Vergara Dauden, M., Machin, S.A. \& Vermylen, J. (1980). A plasma factor in uraemia which stimulates prostacyclin release from cultured endothelial cells, Thrombox. Res., 19, 695-699.

20. Roth, G.J., Stanford, N. \& Majerus, P.W. (1975). Acetylation of prostaglandin synthetase by aspirin, Proc. natl. acad. Sci. USA, 72, 3073-3076.

21. Jaffe, E.A. \& Weksler, B.B. (1979). Recovery of endothelial cell prostacyclin production after inhibition by low doses of aspirin, J. clin. Invest., 63, 532-535.

22. Preston, F.E., Whipps, S., Jackson, C.A., French, A.J., Wyld, P.J. \& Stoddard, C.M. (1981). Inhibition of prostacyclin and platelet thromboxane $A_{2}$ after low dose aspirin, New Engl. J. Med., 304, 76-79.

23. Malstem, C., Hamberg, M., Svensson, J. \& Samuelsson, B. (1975). Physiological role of endoperoxide in human platelets. Haemostatic defect due to a platelet cyclooxygenase deficiency. Prox. natl. acad. Sci. USA, 172 1446-1450.

24. Lagarde, M., Bryon, PA., Vargaftig, B.B. \& Dechavane, M. (1978). Impairment of platelet thromboxane $A_{2}$ generation and of the platelet release reaction in two patients with congenital deficiency of platelet cyclo-oxygenase, Brit. J. Haematol., 38, 251-266.

25. Pareti, F.I., Manucci, PM., D'Angelo, A., Smith, J.B., Sautelin, L. \& Galli, G. (1980). congenital deficiency of thromboxane and prostacyclin, Lancet, i, 898-901.

26. Defreyn, G., Machin, S.J., Carreras, L.O., Vergara Dauden, M., Chamone, D.A.F. \& Vermylen, J. (1981). Familial bleeding tendency with partial platelet thromboxane synthetase deficiency : reorientatin of cyclic endoperoxide metabolism, Brit. J. Haematol., 49, 29-41.

27. Vermylen, J., Defreyn, G., Carreras, L.O., Machin, S.J., Van Schaeren, J. \& Verstraete, M. (1981). Thromboxane Synthetase inhibition as antithrombotic strategy, Lancet, i, 1073-1075.

28. Bowie, E.W., Thompson, J.H., Cascuzzi, P.A. \& Owen, G.A. (1963). Thrombosis in SLE despite circulating anticoagulants, J. Lab. clin. Med., 62, 416-430.

29. Veltkamp, J.J., Kerkhoven, P. \& Loeliger, E.A. (1973). Circulating anticoagulant in disseminated lupus erythematosus, Haemostasis, 2, 253-259.

30. Lechner, K. (1969). A new type of coagulation inhibitor, Thrombos. Diathes. haemorrh., 21, 482-499.

31. Lechner, K. (1974). Acquired inhibitors in nonhemophilic patients, Haemostasis, 3, 65-93.

32. Schleider, M.A. Nachman, R.L., Jaffe, E.A. \& Coleman, M. (1976). A clinical study of the lupus anticoagulant, Blood, 48, 499-509

33. Much, J.R., Herbst, K.D. \& Rapaport, S.I. (1980). Thrombosis in patients with the lupus anticoagulans, Ann. intern. Med.,92, 156-159.

34. Feinstein, D.I. \& Rapaport, S.I. (1972). Acquired inhibitors of blood coagulation, Prog. Hemostas. Thrombos., 1, 75-95.

35. Nilsson, I.M., Astedt, B., Hedner, U. \& Berezin, D. (1975). Intrauterine death and circulating anticoagulant ("antithromboplastin"), Acta med, Scand., 197, 153-159.

36. Carreras, L.O., Defreyn, G., Machin, S.J., Vermylen, J., Deman, R, Spitz, B. \& Van Assche, A. (1981). Recurrent arterial thrombosis, repeated intrauterine death and "lupus" anticoagulant. Detection of an immunoglobulin interfering with prostacyclin formation, Lancet, i, 224-246.

37. Remuzzi, G., Mecca, G., Livio, M., de Gaetano, M., Donati, M.B., Pearson, J.D. \& Gordon, J.L. (1980). Prostacyclin generation by cultured endothelial cells in haemolytic uraemic syndrome, Lancet, i, 656-657.

38. Remuzzi, G., Misiani, R., Marchesi, D., Livio, M., Mecca, G. \& de Gaetano, G. (1978). Haemolytic-uraemic syndrome. Deficiency of plasma factor(s) regulating prostacyclin activity? Lancet, ii, 871-872.

39. Remuzzi, G., Marchesi, D., Misiani, R., Mecca, G., De Gaetano, G. \& Donati, M.B. (1979). Familial deficiency of a plasma factor stimulating vascular prostacyclin activity, Thrombos. Res., 16, 517-525.

40. Machin, S.J., Defreyn, G., Chamone, D.A.F. \& Vermylen, J. (1980). Plasma 6-keto- $\mathrm{PGF}_{1}$ levels after plasma exchange in thrombotic thrombocytopenic purpura, Lancet, i, 661 (Letter).

41. Chamone, D.A.F., Proesmans, W., Mommens, L., Binda, K.M. \& Vermylen, J. Deficient release of prostacyclin-like activity from rat aorta by plasma from infants and children with haemolytic uraemic syndrome. Normalisation upon remission of the disease. Submitted.

42. Carreras, L.O., Chamone, D., Klerckx, P. \& Vermylen, J. (1980). Decreased vascular prostacyclin $\left(\mathrm{PGI}^{2}\right)$ in diabetic rats. Stimulation of $\mathrm{PGI}_{2}$ release in normal and diabetic rats by the antithrombotic compound Bay g 6575, Thrombos. Res., 19, 663-670.

43. Moncada, S., Bunting, S., Mullane, K., Thorogood, P., Vane, J.R., Ray, A. \& Needleman, P. (1977). Imidazole : selective inhibitor of thromboxane synthetase, Prostaglandins, 13, 611-618.

44. Chamone, D.A.F., Vermylen, J. \& Verstraete, M. (1979). Bay $g$ 6575, an antithrombotic compound that stimulates prostacyclin release from the vessel wall, Thrombos. Haemost., 42, 369-369.

45. Vermylen, J., Chamone, D.A.F. \& Verstraete, M. (1979). Stimulation of prostacyclin release from vessel wall by Bay $\mathrm{g}$ 6575, an antithrombotic compound, Lancet, i, 518-520. 